\title{
Personality Factors as Determinants of Adjustment Among Military Children
}

\author{
Kaaveri Dhingra ${ }^{1}$, Yashwant Kumar Nagle $^{2}$ \\ ${ }^{1}$ Department of Psychology, Cambridge School, Srinivaspuri, New Delhi, India \\ ${ }^{2}$ Scientist ${ }^{\circ}$ ' Department of Psychology, 22 Services Selection Board, Sultania Infantry Lines, Bhopal, India
}

Email address:

yknagle@gmail.com (Y. K. Nagle)

To cite this article:

Kaaveri Dhingra, Yashwant Kumar Nagle. Personality Factors as Determinants of Adjustment Among Military Children. American Journal of Applied Psychology. Vol. 8, No. 1, 2019, pp. 1-7. doi: 10.11648/j.ajap.20190801.11

Received: December 16, 2018; Accepted: January 31, 2019; Published: March 15, 2019

\begin{abstract}
Families of service personnel are unique. Frequent moves, the potential of being deployed into hostile environments, long periods of family separation are some of the life stressors faced by them. The majority of researches in the area of military have focused on the family experience. The Personality and Adjustment patterns of children of service personnel remain unexplored specifically in Indian context. The objective of the present research is to compare the Personality and Adjustment patterns of children of non- Air Force Personnel and Air Force Personnel. In order to address the delineated research questions, a total sample of 82 adolescents from different Air Force schools in Delhi were chosen using random sampling. The sample comprised of 41 children of Non- Air Force Personnel and 41 children of Air Force Personnel. The age range was 15-17 years. The data was gathered using standardized questionnaires: HEXACO-PI 60 Items, Self Report form and Bell Adjustment Inventory. The data was analyzed using Pearson coefficient for finding the correlations between Personality factors and Adjustment and Multiple Regression Analysis was used to find which Personality factors are predicting emotional and social adjustment. It was found that there was a significant difference among children of Air Force Personnel and non-Air Force Personnel only with respect to Extraversion and Openness to Experience dimensions of Personality and Emotional dimension of Adjustment. Results from regression analysis revealed that Emotionality factor of Personality is a significant predictor of Emotional Adjustment $(\mathrm{p}<.001)$ which is explained by $12.5 \%$ variance. The findings of the research have further been discussed and related to the previous researches in this area.
\end{abstract}

Keywords: Adolescents, Personality, Adjustment, Air Force Personnel

\section{Introduction}

\subsection{Military Psychology}

Military Psychology is defined by the application of psychological principles and theories to the military context. It is a broad, complex, and specialized field where knowledge gained from various other branches of psychology (for example, experimental, social, clinical, organizational, and personality) converges. Military Psychology includes a vast array of activities in psychological research, assessment, and treatment. Concerns that are relevant for industrial-organizational psychology and the issues of assessment, diagnosis and treatment as understood through clinical psychology form important aspects of Military Psychology endeavors, since developments in these research areas directly help the military in managing the huge manpower inherent in it. Yet, Military Psychology, by virtue of its vastness and variedness, goes much beyond these and explores specific and special concerns unique to the military environment. It is, therefore, a unique opportunity that Military Psychology offers to a researcher to be able to explore the domains of basic as well as applied research at the same time. [1]

\subsection{Emotional and Social Development}

Emotional development is closely entwined with cognitive development. Emotional maturity is the ability to express emotional affect appropriately and demonstrate positive coping responses to stress. Adolescent emotional development is characterized by the establishment of a 
realistic and coherent sense of identity while learning to cope with stress and manage rapidly fluctuating emotions. [2] Erickson in [2] posited that establishing a sense of self was the central task of adolescence. Identity includes one's selfconcept and self-esteem. Self-concept refers to the set of beliefs, qualities and abilities one has about her/his selfwhereas self-esteem refers to a value judgment by evaluating how one feels about one's self-concept. Adolescents emerging cognitive abilities allow them to make generalizations about themselves. At this time the conflict with parents is common. For adolescents in military families communication with parents about emotional issues may be difficult due to the military culture of persistence, where one is expected to deal with problems without complaint. This may be aggravated by the fact that parenting style is authoritative in most military families. There are additional stressors when a member is deployed for example, taking on the roles and responsibilities of caring for the younger sibling and at home parent. Since the adolescents cognitive development allows them to think about the consequences of deployment, they may be more aware of what is happening to their parent. These challenges are likely to impact adolescents' ability and success in navigating their emotional development. [3]

During this period adolescents' thoughts, emotions and identities are becoming more complex as a result their social relationships also become more complicated. Adolescents' social development is characterized by a shift in orientation to peer relationships which is necessary in order to develop a sense of autonomy and freedom. Romantic relationships, intimacy and initiation of sexual behavior are typical during adolescence. Healthy social development involves the ability to achieve balance and satisfaction with interpersonal. However adolescent's success in developing healthy social relationships is influenced by their parents. When parents are emotionally unavailable (in case of most military families) they may have difficulties in forming intimate relationships. Therefore the accessibility of the parent is important to successful adolescent development.

\subsection{Military Life and Deployment}

Military families are unique. Frequent moves, the potential of being deployed into hostile environments, long periods of family separation are some of the life stressors faced by them. In this scenario, the children and the youth left at home are most vulnerable. They face the possibility of a prolonged separation and possible loss of a parent when the service member is deployed, but also they are likely to experience transformations and disruptions generally. [4] Significant parental absence in turn leads to elevated levels of stress and various psychological issues. Teenagers with a deployed parent also report significantly more psychosocial internalizing symptoms, externalizing symptoms and school problems than did those with non-deployed background.[5] A survey revealed that thoughts of suicide and incidence of depression were reported more by adolescents in deployed families as compared to their civilian and non-deployed military counterparts.[6] In terms of parenting also it has an impact when the at home spouse is solely responsible for the children. In a study of 97 recently deployed soldiers, at home parents reported a stressful parenting.[7] The issue is not only limited till the period of deployment but concerns also crop up after reintegration. In one qualitative study, fathers expressed the same concern and reported difficulty in reconnecting and resuming their role after deployment. [8]

The present study looks into the adjustment patterns (emotional and social) and Personality of children of Air Force Personnel and are there any differences among them and the civilian population. Since adolescence is a crucial stage in terms of developmental and emotional growth the results from this exploratory study can be useful for developing intervention programs for air force children in order to optimize their mental health if there are any differences. And also to look for personality factors that account for social and emotional adjustment in order to facilitate their well-being.

Based on the rationale certain objectives have been delineated.

1. To explore the differences in emotional adjustment between children of Air Force Personnel and non-Air Force Personnel.

2. To explore the differences in social adjustment between children of Air Force Personnel and children of nonAir Force Personnel.

3. To explore the differences in six domains of Personality between children of Air Force Personnel and non-Air Force Personnel.

4. To explore the correlation between six domains of personality, emotional and social adjustment.

\section{Method}

\subsection{Participants}

A total sample of 82 (Males $=36$ and Females=46) adolescents was taken from different Air -Force schools in Delhi. A total sample of children of Air Force Personnel comprised of 41 adolescents (Males=18 and Females= 23) and a total sample of children of Non-Air Force Personnel comprised of 41 adolescents (Males=18 and Females= 23). The age range was $15-17$ years, with mean age of $M=16.63$; $\mathrm{SD}=0.63$ and $\mathrm{F}=16 ; \mathrm{SD}=0.67$ of children of non-Air Force Personnel and $\mathrm{M}=16.05 ; \mathrm{SD}=0.87$ and $\mathrm{F}=16.15 ; \mathrm{SD}=0.78$ of children of Air Force Personnel. The participants were chosen using random sampling.

\subsection{Measures}

In the present study following measures were used:

\subsubsection{Demographic Questionnaire}

A demographic questionnaire was prepared to gather personal details of the participants like name, age etc.

\subsubsection{HEXACO-PI}

Based on lexical approach HEXACO-PI-R is developed by 
[9] comprised of 60 items (self-report form) majoring six dimensions of personality Honesty-Humility, Emotionality, Extraversion, Agreeableness, Consciousness and Openness to Experience. The participants are asked to rate each of the sixty items on a 5 point Likert scale, where $5=$ Strongly Agree, 4= Agree, 3= Neutral, 2=Disagree, 1= Strongly Disagree. Examples of items in each dimension are: Honesty Humility (Item 6- I wouldn't use flattery to get a raise or promotion at work, even if I thought it would succeed), Emotionality (Item 11- I sometimes can't help worrying about little things), Extraversion (Item 16- I prefer jobs that involve active social interaction to those that involve working alone), Agreeableness (Item 3-I rarely hold a grudge, even against people who have badly wronged me), Conscientiousness ( Item 14- When working on something, I don't pay much attention to small details), Openness to Experience (Item 1-I would be quite bored by a visit to an art gallery). The reliability of HEXACO-PI is.574

\subsubsection{Bell Adjustment Inventory (Student Form)}

The Bell's Adjustment Inventory [10] is one of the most widely used measures of adjustment and is an effective screening device for identifying adjustment problems. It provides four separate measures of personal and social adjustment: Home, Health, Social and Emotional Adjustment. In the present study only items measuring social and emotional adjustment are included. A total of 69 items are included 34 items for social adjustment and 35 items for emotional adjustment. The participants were asked to respond to items in both dimensions by marking a circle on either 'Yes', 'No' or '?'. Examples of items in each dimension are: Emotional Adjustment (Item 1- Do you day dream frequently; Item 5- Do you frequently have spells of the "blues") and Social Adjustment (Item 2- Do you enjoy social gatherings just to be with people; Item 4- Do you take responsibility for introducing people at a party). The reliability of Bell Adjustment inventory is.535.

\section{Results}

Table 1. Mean scores on two dimensions of adjustment of children of non-air force and air-force personnel and result of $F$ test.

\begin{tabular}{|c|c|c|c|c|c|c|c|}
\hline Variables & Groups & $\mathbf{N}$ & Mean & SD & df & $\mathbf{F}$ & $P$ value \\
\hline Emotional Adjustment & $\begin{array}{l}\text { Children of Non-Air Force Personnel } \\
\text { Children of Air Force Personnel }\end{array}$ & $\begin{array}{l}41 \\
41\end{array}$ & $\begin{array}{l}16.32 \\
12.90\end{array}$ & $\begin{array}{l}7.237 \\
6.971\end{array}$ & 1 & 4.735 & $.033 *$ \\
\hline Social Adjustment & $\begin{array}{l}\text { Children of Non-Air Force Personnel } \\
\text { Children of Air Force Personnel }\end{array}$ & $\begin{array}{l}41 \\
41\end{array}$ & $\begin{array}{l}16.20 \\
15.71\end{array}$ & $\begin{array}{l}3.783 \\
4.119\end{array}$ & 1 & .312 & .578 \\
\hline
\end{tabular}

Table 2. Mean scores onsixdimensionsofpersonalityofchildrenofnon-airforceandair-forcepersonnelandresultofFtest.

\begin{tabular}{|c|c|c|c|c|c|c|c|}
\hline Variables & Groups & $\mathbf{N}$ & Mean & SD & df & $\mathbf{F}$ & P value \\
\hline \multirow{2}{*}{ Honesty Humility } & Children of Non-Air Force Personnel & 41 & 33.83 & 6.511 & \multirow{2}{*}{1} & \multirow{2}{*}{.287} & \multirow{2}{*}{.593} \\
\hline & Children of Air Force Personnel & 41 & 34.63 & 7.074 & & & \\
\hline \multirow{2}{*}{ Emotionality } & Children of Non-Air Force Personnel & 41 & 30.20 & 5.959 & \multirow{2}{*}{1} & \multirow{2}{*}{3.428} & \multirow{2}{*}{.068} \\
\hline & Children of Air Force Personnel & 41 & 27.76 & 5.970 & & & \\
\hline \multirow{2}{*}{ Extraversion } & Children of Non-Air Force Personnel & 41 & 32.22 & 6.475 & \multirow{2}{*}{1} & \multirow{2}{*}{6.486} & \multirow{2}{*}{$.013 * *$} \\
\hline & Children of Air Force Personnel & 41 & 35.51 & 5.158 & & & \\
\hline Agreeableness & Children of Non-Air Force Personnel & 41 & 32.20 & 4.844 & 1 & .140 & .709 \\
\hline \multirow{2}{*}{ Conscientiousness } & Children of Non-Air Force Personnel & 41 & 32.37 & 4.340 & \multirow{2}{*}{1} & \multirow{2}{*}{1.386} & \multirow{2}{*}{.243} \\
\hline & Children of Air Force Personnel & 41 & 33.88 & 6.986 & & & \\
\hline \multirow{2}{*}{ Openness to Experience } & Children of Non-Air Force Personnel & 41 & 31.51 & 4.712 & \multirow{2}{*}{1} & \multirow{2}{*}{5.626} & \multirow{2}{*}{$.020 *$} \\
\hline & Children of Air Force Personnel & 41 & 34.37 & 6.094 & & & \\
\hline
\end{tabular}

Table 3. Depicting correlations between personality factors and dimensions of adjustment.

\begin{tabular}{|c|c|c|c|c|c|c|c|c|}
\hline VARIABLES & HON_HUM & EMOTIONALITY & EXT & AGR & CON & OTE & SOCIAL & EMOTIONAL \\
\hline \multicolumn{9}{|l|}{ HON_HUM } \\
\hline $\mathrm{EMO}^{-}$ & .176 & & & & & & & \\
\hline EXT & .095 & $-.250^{*}$ & & & & & & \\
\hline AGR & $.332^{* *}$ & -.194 & .174 & & & & & \\
\hline $\mathrm{CON}$ & .167 & -.110 & $.527^{* *}$ & $.339^{* *}$ & & & & \\
\hline OTE & $.310^{* *}$ & -.077 & $.500^{* *}$ & $.286^{* *}$ & $.542^{* *}$ & & & \\
\hline SOCIAL & -.101 & .069 & -.109 & .077 & .000 & .092 & & \\
\hline MEAN & 34.23 & 28.98 & 33.87 & 32.43 & 33.12 & 32.94 & 15.95 & 14.61 \\
\hline SD & 6.77 & 6.05 & 6.04 & 5.57 & 5.83 & 5.60 & 3.93 & 7.26 \\
\hline
\end{tabular}

$p<.01 * *, p<.05 *$.

There is a significant correlation between Personality factors namely Emotionality and Extraversion with Emotional Adjustment. The correlations between the personality factors and adjustment at.05 and.01 levels of significance showed that Emotionality has a significant positive correlation (EMO-.353) with Emotional Adjustment. Extraversion is negatively correlated with Emotional Adjustment (EXT -.229). 
Table 4. Regression results of personality factors with social adjustment.

\begin{tabular}{llllll}
\hline PREDICTORS & $\boldsymbol{\beta}$ & $\mathbf{R}^{2}$ & $\boldsymbol{\Delta R}^{\mathbf{2}}$ & $\mathbf{F}$ & $\boldsymbol{p}$ \\
\hline Honesty-Humility & -.101 & .010 & -.002 & .825 & .366 \\
Emotionality & 0.69 & .005 & -.008 & .381 & .539 \\
Extraversion & -.109 & .012 & .000 & .964 & .329 \\
Agreeableness & .077 & .006 & -.007 & .476 & .492 \\
Conscientiousness & .000 & .000 & -.012 & .000 & .998 \\
Openness to experience & .092 & .008 & -.004 & .678 & .413 \\
\hline
\end{tabular}

As shown in table 4 none of the Personality factors is significantly predicting social adjustment in children of nonAir Force Personnel and Air Force Personnel.

Table 5. Regression results of personality factors with emotional adjustment.

\begin{tabular}{llllll}
\hline PREDICTORS & $\boldsymbol{\beta}$ & $\mathbf{R}^{\mathbf{2}}$ & $\mathbf{\Delta R}^{\mathbf{2}}$ & $\mathbf{F}$ & $\boldsymbol{p}$ \\
\hline Honesty- & -.102 & .010 & -.002 & .838 & .363 \\
Humility & .353 & .125 & .114 & 11.377 & $.001^{* * *}$ \\
Emotionality & -.229 & .053 & .041 & 4.438 & .038 \\
Extraversion & -.005 & .000 & -.012 & .002 & .962 \\
Agreeableness & -.012 & .000 & -.012 & .011 & .915 \\
Conscientiousne & & & & & .348 \\
ss & -.066 & .004 & -.008 & .347 \\
Openness to & & & & & .557 \\
\hline
\end{tabular}

$p<.001 * * *$.

As shown in table 5, emotionality factor of Personality is a significant predictor of emotional adjustment $(p<.001)$ in children of non- Air Force Personnel and Air Force Personnel which is explained by $12.5 \%$ variance.

\section{Discussion}

Individuals scoring high tend to be unstable emotionally. Persons with low scores tend to be emotionally stable. The mean score of group 3 is 16.32 and the mean score of group 4 is 12.90 on emotional dimension of adjustment with an $\mathrm{F}$ value of 4.735 . This means that there is a significant difference between the two groups with respect to Emotional dimension of Adjustment. However the mean score of group 4 is lower than the mean score of group 3 indicating better emotional adjustment. Although many studies have reported that the emotional adjustment of children in military families in negatively impacted. These studies suggest a heavy mental toll that children from service background have to pay. But on the other hand there are empirical studies suggesting that children from service background are more resilient and well adjusted. One review of research found that, compared with their civilian counterparts, military connected youth function better than other children in several domains that help build resilience, including self-regulation, intellectual and academic performance, and emotional wellbeing. [11] A recent study investigated how 1,500 military-connected youth, ages 11-17, coped with deployment, two-thirds of them reported no emotional difficulties. [12]

Individuals scoring high tend to be submissive and retiring in the social contacts. Individuals with low scores tend are aggressive in social contacts. The mean score of group 3 is 16.20 and the mean score of group 4 is 15.71 with an F value of .312. Although the mean of group 3 is slightly higher than the mean of group 4 but the $F$ value is not significant this means that there is no difference between the two groups with respect to Social dimension of Adjustment. However, the mean score of group 4 is lower than the mean score of group 3 indicating better social adjustment. The results of the present study contradict the results of previous studies which suggest that the most commonly mentioned stressor related to mobility is challenge of making and maintaining friendships. The reason that children of air force personnel are better socially adjusted could probably be the institutional life that they live. There is more openness and cohesiveness due to frequent moves. On one hand they get separated from the previous relationships but because of ample of opportunities to travel and explore they create new bonds maintaining the previous ones.

Persons with very high scores on the Honesty-Humility scale avoid manipulating others for personal gain, feel little temptation to break rules, are uninterested in lavish wealth and luxuries, and feel no special entitlement to elevated social status. Conversely, persons with very low scores on this scale will flatter others to get what they want, are inclined to break rules for personal profit, are motivated by material gain, and feel a strong sense of self-importance. According to the norms of HEXACO-PI 60 items scale, 43 is considered to be a high score and 31.94 is considered to be a low score.

The mean score of group 3 is 33.83 and the mean score of group 4 is 34.63 which is almost the same this means that there is no difference between the two groups with respect to Honesty Humility dimension of Personality. The mean score of both group 3 and group 4 is relatively average which means that both the groups on Honesty Humility dimension neither flatter nor manipulate others to get what they want, feel little temptation to break rules for personal profit, are not that motivated by material gain, and feel a strong sense of self-importance. However the mean score of group 4 is slightly higher than the mean score of group 3 . The reasons for such differences could be numerous. Children of service personnel may experience a different kind of discipline than children of civilian Personnel. Many parents strive to instill the values of loyalty, duty, respect, selflessness, honor, integrity and courage, in their children through high expectations and firm disciplinary action. Some military parents emphasize clear rules and consequences while still building in flexibility and collaboration with their children.

Persons with very high scores on the Emotionality scale experience fear of physical dangers, experience anxiety in response to life's stresses, feel a need for emotional support from others, and feel empathy and sentimental attachments with others. Conversely, persons with very low scores on this scale are not deterred by the prospect of physical harm, feel little worry even in stressful situations, have little need to share their concerns with others, and do not feel emotionally detached from others. According to the norms of HEXACOPI 60 items scale, 42.29 is considered to be a high score and 36.85 is considered to be a low score. 
The mean score of group 3 is 30.20 and the mean score of group 4 is 27.76. Although the mean score of group 3 is higher as compared the group 4 but the $F$ value is not significant this means that there is no significant difference between two groups with respect to Emotionality dimension of Personality.

The mean score of both group 3 and group 4 is low, this means that children are not deterred by the prospect of physical harm, feel little worry even in stressful situations, have little need to share their concerns with others, and do not feel emotionally detached from others. However, the mean score of group 4 is lower than the mean score of group 3. The low mean score in children of Air Force Personnel can be attributed to sources of strength that they utilize to maintain their mental health. Despite the negative impact that family circumstances have on military children but on the positive side these children are also resilient. [13] Most children of Air Force Personnel lived with both the parents. In other words the service member is posted in Delhi only.

Persons with very high scores on the Extraversion scale feel positively about themselves, feel confident when leading or addressing groups of people, enjoy social gatherings and interactions, and experience positive feelings of enthusiasm and energy. Conversely, persons with very low scores on this scale consider them-selves unpopular, feel awkward when they are the center of social attention, are indifferent to social activities, and feel less lively and optimistic than others do. According to the norms of HEXACO-PI 60 items scale, 40.15 is considered to be a high score and 30.21 is considered to be a low score.

The mean score of group 3 is 32.22 which is lower than the mean score of group 4 (35.51) which mean that there is a significant difference between two groups with respect to Extraversion dimension of Personality. The same is also indicated by the $\mathrm{F}$ value of 6.486 .

The mean score of group 3 and 4 is average, this means that children feel positively about themselves, feel confident when leading or addressing groups of people, enjoy social gatherings and interactions, and experience positive feelings of enthusiasm and energy. However, the mean score of group 4 is higher than the mean score of group 3. The higher score can be attributed to several reasons. Firstly, military families move frequently than civilian families. Changing schools and towns can offer military children several opportunities to try out different activities, explore new social relationships. A study of 608 Army and Air Force families with children ages 10-17 found that certain individual characteristics and social relationships improved when a family had to move. [13]

Persons with very high scores on the Agreeableness scale forgive the wrongs that they suffered, are lenient in judging others, are willing to compromise and cooperate with others, and can easily control their temper. Conversely, persons with very low scores on this scale hold grudges against those who have harmed them, are rather critical of others' shortcomings, are stubborn in defending their point of view, and feel anger readily in response to mistreatment. According to the norms of HEXACO-PI 60 items scale, 41.5 is considered to be a high score and 33.04 is considered to be a low score.

The mean score of group 3 is 32.20 and the mean score of group 4 is 32.66 . Since the mean score of both the groups is same this means that there is no difference between the two groups with respect to Agreeableness dimension of Personality.

The mean score of both group 3 and group 4 is low, this means children hold grudges against those who have harmed them, are rather critical of others' shortcomings, are stubborn in defending their point of view, and feel anger readily in response to mistreatment. The reason for such a low score in both the groups can be attributed to the stage of adolescents. This period marks rapid growth in almost all domains. As Erickson pointed out that establishing a sense of identity was a central task of adolescents. Adolescents emerging cognitive abilities allow them to make generalizations about themselves. This is the major reason why adolescents are critical of other's shortcoming are stubborn in defending their point of view. If we look at the parenting styles in military families it is mainly authoritative and restrictive. On one hand it nurture discipline in them but on the other hand, communication with parents may be difficult due to the military culture of persistence, where one is expected to deal with problems without complaint. [3]

Persons with very high scores on the Conscientiousness scale organize their time and their physical surroundings, work in a disciplined way toward their goals, strive for accuracy and perfection in their tasks, and deliberate carefully when making decisions. Conversely, persons with very low scores on this scale tend to be unconcerned with orderly surroundings or schedules, avoid difficult tasks or challenging goals, are satisfied with work that contains some errors, and make decisions on impulse or with little reflection. According to the norms of HEXACO-PI 60 items scale, 40.63 is considered to be a high score and 30.61 is considered to be a low score.

The mean score of group 3 is 32.27 and the mean score of group 4 is 33.88 . Although the mean score of group 4 is slightly higher than the mean score of group 3 but the F value is not significant this means that there is no significant difference between the two groups with respect to Conscientiousness dimension of Personality.

The mean score of both group 3 and group 4 is average, this means children are averagein organizing their time and their physical surroundings, work in a disciplined way toward their goals, are satisfied with work that contains some errors and at times strive for accuracy and perfection in their tasks, and deliberate carefully when making decisions. However, the mean of group 4 is higher than the mean score of group 3. The reasons for such results can also be attributed to the kind of background and parenting styles military families inculcate.

Persons with very high scores on the Openness to Experience scale become absorbed in the beauty of art and nature are inquisitive about various domains of knowledge, use their imagination freely in everyday life, and take an interest in unusual ideas or people. Conversely, persons with 
very low scores on this scale are rather unimpressed by most works of art, feel little intellectual curiosity, avoid creative pursuits, and feel little attraction toward ideas that may seem radical or unconventional. According to the normsof HEXACO-PI 60 items scale, 33.11 is considered to be a high score and 22.69 is considered to be a low score.

The mean score of group 3 is 31.51 and the mean score of group 4 is 34.37 . Since the mean score of group 4 is higher than the mean score of group 3 this means that there is a significant difference between the two groups with respect to Openness to Experience dimension of Personality. This is also indicated by the $\mathrm{F}$ value of 5.626. The mean score of both the groups is high this means children become absorbed in the beauty of art and nature are inquisitive about various domains of knowledge, use their imagination freely in everyday life, and take an interest in unusual ideas or people. However the mean score of group 4 is higher than the mean of group 3. The reasons for such differences can be attributed to mobility as military families move frequently which give them ample amount of exposure and ways to explore new activities. [14]

Emotionality has a significant positive correlation (EMO.353) with Emotional Adjustment. Extraversion is negatively correlated with Emotional Adjustment (EXT -.229).

As shown in table 4 none of the Personality factors is significantly predicting social adjustment in children of nonAir Force Personnel and Air Force Personnel. However, as shown in table 5, emotionality factor of Personality is a significant predictor of emotional adjustment $(p<.001)$ in children of non- Air Force Personnel and Air Force Personnel which is explained by $12.5 \%$ variance. A study exploring the levels of university adjustment and its relation to the characteristics of extroversion and neuroticism using a sample of 344 students in Singapore found that that neuroticism managed to predict $16 \%$ of explained variance in emotional adjustment. [15]

\section{Conclusion}

The present study aimed to explore the personality and adjustment patterns of children of non-air force personnel and children of air force personnel. Significant differences were found among children of Air Force Personnel and nonAir Force Personnel only with respect to Extraversion and Openness to Experience dimensions of Personality and Emotional dimension of Adjustment. A chief finding in group differences was that group 4 scored higher on honesty humility, extraversion, agreeableness, conscientiousness and openness to experience indicating a better overall personality picture as compared to children of non-air force personnel. Considering the dimensions of adjustment, their mean score was lower as compared to their civilian counterparts indicating better emotional and social adjustment. The chief reasons for such findings could be first the family environment and the institutional life in which they are brought up. The results from this study calls for an equally imperative need to focus on adolescents as a group because the problems shared by the adolescents are similar in almost every sense. In addition, significant studies have also indicated the crucial role of both the parents in child's holistic development, as a community it is important to be sensitive to the unique needs of military families during these times of transition. More research using diverse samples is needed to understand and address the needs of military families with young children at micro (intrapersonal) and macro (familial) level.

\section{References}

[1] Mukherjee, S., Kumar, U., \& Mandal, M. K. Status of military psychology in India: A Review. Journal of the Indian Academy of Applied Psychology. Vol. 35, No. 2, 2009, pp. 181-194.

[2] Santrock, J. W. The self, identity, emotion, and personality. In: Santrock, Adolescence. New York: McGraw-Hill; 2010.

[3] Milburn, N. G., \& Lightfoot, M. Adolescents in wartime U.S. military families: A developmental perspective on challenges and resources. Clinical Child and Family Psychology Review. Vol. 16, No. 3, 2013, pp. 266-277.

[4] Mmari, K., Roche, K. M., Sudhinaraset, M., \& Blum, R. When a parent goes off to war: Exploring the issues faced by adolescents and their families. Youth \& Society. Vol. 40, No. 4, 2009, pp. 455-475.

[5] Aranda M. C., Middleton L. S., Flake E., Davis B. E. Psychosocial screening in children with wartime-deployed parents. Military Medicine. Vol. 176, No. 4, 2011, pp. 402407.

[6] Reed S. C., Bell J. F., Edwards T. C. Adolescent well-being in Washington state military families. American Journal of Public. Vol. 101, No. 9, 2011, pp. 1676-1682.

[7] Khaylis A, Polusny MA, Erbes CR, Gewirtz AH, Rath M. Posttraumatic stress, family adjustment, and treatment preferences among National Guard soldiers deployed to OEF/OIF. Military Medicine. Vol. 176, No. 2, 2011, pp. 126131.

[8] Willerton E, Schwarz RL, Wadsworth SM, Oglesby MS. Military fathers' perspectives on involvement. Journal of Family Psychology. Vol. 25, No. 4, 2011, pp. 521-530.

[9] Lee, K., \& Ashton, M. C, The hexaco personality inventory, Scale Desciptions, 2009 [cited 2016 Jun 30]. Available from: http://hexaco.org/scaledescriptions

[10] Bell, H. M, Bell adjustment inventory manual, 1963, Consulting Psychologists Press [cited 2016 Jun 30]. Available from:

https://books.google.co.in/books/about/Bell_Adjustment_Inve ntory.html?id=sh3GXwAACAAJ\&redir_esc $=y$

[11] Park, N. Military children and families: strengths and challenges during peace and war. Army Psychology, Vol. 66, No. 1, 2011, pp. 65-72.

[12] Chandra, A., Lara-Cinisomo, S., Jaycox, L. H., Tanielian, T., Han, B., Burns, R. M., \& Ruder, T. Views from the Homefront: The experiences of youth and spouses from military families. Santa Monica: RAND Corporation. 2011. 
[13] Easterbrooks, A. M., Ginsburg, K., \& Lerner, R. M. Resilience among military youth. Military children and families. Vol. 23, No. 2, 2011, pp. 99-120.

[14] Kelly, M. L., Finkel, L. B., \& Ashby, J. Geographical mobility, family and maternal variables as related to the psychosocial adjustment of military children. Mlitary Medicine. Vol. 168, No. 12, 2003, pp. 1019-24.
[15] Hmaidan, Y. A., \& Al-Zoubi, M. University adjustment and its relation to the characteristics of extroversion and neuroticism. International Proceedings of Economics Development and Research. 2014, pp. 37-44. 